\title{
Factors Affecting the Organizational Adoption of Secure Community Cloud in KSA
}

\author{
Nouf S. Aldahwan $\mathbb{D}^{1,2}$ and Muhammed S. Ramzan ${ }^{1}$ \\ ${ }^{1}$ Department of Information System, King Abdulaziz University, Jeddah, Saudi Arabia \\ ${ }^{2}$ Department of Information System, King Khaled University, Abha, Saudi Arabia
}

Correspondence should be addressed to Nouf S. Aldahwan; naldhwan@kku.edu.sa

Received 15 July 2021; Revised 17 August 2021; Accepted 28 August 2021; Published 10 September 2021

Academic Editor: Chien Ming Chen

Copyright ( 2021 Nouf S. Aldahwan and Muhammed S. Ramzan. This is an open access article distributed under the Creative Commons Attribution License, which permits unrestricted use, distribution, and reproduction in any medium, provided the original work is properly cited.

\begin{abstract}
Cloud computing is an innovative technology and gaining popularity in variety of organization to meet their computing requirements. Saudi Arabia is considered as the Gulf region's high economy and the future market for cloud computing technologies. Analysis of its economic benefits, adequacy from technical, organizational, and environmental viewpoints, and possible challenges should precede the implementation of new technologies. Latest research and developments on cloud computing are causally linked to the emphasis on applications, advantages, expenditures, and technology. The community cloud (CC) is an impressive replacement for different organizations as it promotes cost reduction and quality enhancement. However, this research was performed to study the perception of IT and telecommunications company employees and computer users who support community cloud. The current state of community cloud adoption in KSA is analyzed. Present challenges impact the adoption of community cloud in Saudi Arabia and define the motivation factors. Questionnaires were used to accomplish these goals. Questionnaires were designed to accomplish these goals and it is implemented using survey. Questions about confidence are also a key issue. Issues such as data privacy, integrity, and availability are the factors influencing the organization's acceptance of community cloud.
\end{abstract}

\section{Introduction}

For about half a century, since the dawn of the computing era, disruptive multicore technology has created the urge and need for computational science society and software vendors to comprehend and exploit concurrency. The focus is no longer on developing faster clock rates but designing algorithms and applications helps to effectively use the multiple cores of the modern processor. The need and urge have begotten the idea of cloud computing. According to Marinescu [1], cloud computing is a model for improving pervasive, quick, on-demand network access to a communal pool of connected computing resources, such as servers, services, applications, and storage, that can be quickly set up and freed with the least amount of management effort or interaction from providers. Cloud computing eon began in 2006 after the Amazon Web Services (AWS) developed the
Elastic Cloud Computing (EC2) and the Simple Storage Service (S3). Since then, the cloud computing program has been inspired by the knowledge that large computing and storage farms can efficiently process and store data that are retrievable through the Internet. Cloud computing enables local to network-centric computing and content, with storage and processing resources provided by remote data centers. Users of cloud computing, as a result, hand over control of their data and code to cloud service providers. Furthermore, cloud computing provides metered storage and computation capabilities, allowing clients to pay only for the services they utilize [1]. Beside the cloud advantages, the main obstacles impeding the widespread adoption of cloud computing are security, confidentiality, integrity, availability, and trust issues [2].

Information technology has evolved over time, resulting in cloud computing concept. This was identified as one of the 
primary computing models, and various educational and industrial groups were more interested in researching the effective paradigm [3].

Many developed countries have implemented cloud computing, which has resulted in improved government functions, citizen and organization services, and international cooperation. Even while cloud computing is no longer regarded as a cutting-edge technology in developed countries, it marks a paradigm shift for developing and poor countries. In 2016, according to O'Connell, the Communications and Information Technology Commission (CITC), Saudi Arabia's communications watchdog, dispensed a cloud computing regulatory framework. In 2018, the National Cybersecurity Agency (NCA) also issued broad restrictions on the usage of cloud computing services that were based outside Saudi Arabia, a move that raised concerns for cloud users and service providers. In February 2019, the Ministry of Communications and Information Technology issued the country's first cloud policy that formed the basis for the adoption of cloud services at the state level. However, the policy's state is still marked as a draft, and its exact status remains unknown. Nevertheless, the policy goals were to accelerate the adoption of cloud computing amenities by the government and private institutions when making investment decisions regarding information technology, improve efficiency in services offered to the citizens, offer more robust cybersecurity, intensify innovations, and enhance agility and consistency [4].

According to Al-Ruithe et al. [5], despite Saudi Arabia's recent extensive investments aimed at developing its information and technology infrastructure, the country is still lagging in embracing cloud computing. In a study conducted by Al-Ruithe and his colleagues, as of 2018 , about $54.37 \%$ of Saudi Arabians who were interviewed had not adopted cloud computing in their organizations, only $16.50 \%$ had adopted some cloud services in their organizations, while the rest did not know. Still, among those who had not adopted cloud computing, $27.68 \%$ reported that cloud computing was not even being discussed in their agenda or investments, $18.75 \%$ indicated that they did not consider adopting cloud computing services, with only $21.43 \%$ intended to embrace the services in about two years, $15.17 \%$ in a year, and $6.25 \%$ in the next six months. Interestingly, $10.71 \%$ were oblivious of any plans regarding cloud computing. Concerning cloud deployment models in the organizations that had embraced cloud computing, $53.33 \%$ had adopted private cloud (36.67\% within their premises), $35.00 \%$ had private cloud, $10.00 \%$ used community cloud, and $6.67 \%$ used the hybrid cloud, while $6.67 \%$ were not sure. Similarly, regarding the adoption of cloud service models, 58.33\% used SaaS, 56.67\% adopted IaaS, and $28.33 \%$ used PaaS. However, $10.00 \%$ of the respondents did not know which services they were using.

Despite recent major investments in development and extensive efforts to enhance its ICT infrastructure, in terms of community cloud computing, the Kingdom of Saudi Arabia is currently still behind. The goal of this article is to investigate the current state of community cloud adoption in KSA. this study looked at the perspectives of employees in IT and telecommunications firms, as well as users of community cloud-supporting devices, in order to discover motivating factors and current difficulties impacting community cloud adoption in Saudi Arabia.

The purpose of this research is to look at the perspectives of IT and telecommunications professionals, as well as users of cloud computing-supporting devices, of community cloud computing as the future generation of computing technology, as well as the degree of community cloud adoption, and discover motivating factors as well as existing obstacles affecting community cloud adoption in Saudi Arabia. The first section of this paper provides an introduction, while the second section contains brief studies of cloud computing. The community cloud adoption factors will be covered in Section 3. The survey and data collecting will be discussed in Section 4 to meet the research's goals. The fifth section is all about data analysis. The research findings and results will be presented in Section 6. The recommendation and conclusion will be presented in Section 7.

\section{Brief Review of Cloud Computing}

This section reviews cloud computing, the cloud computing service model, and the cloud computing deployment model.

2.1. Cloud Computing Service Model. According to the National Institute of Standards and Technology [6], cloud computing service models include software as a service (SaaS), platform as a service (PaaS), and infrastructure as a service (IaaS). NIST stated that the software as a service only runs software developed by its vendors. SaaS services can be accessed using user interfaces, such as web browsers via stationary and mobile devices. However, users do not manage or control the basic infrastructure of the service model like the network, servers, storage, or operating systems. The services offered under SaaS include enterprise services (including workflow management, desktop software, communications, and supply chain) and web 2.0 applications (including metadata management, blogs, portal services, wiki links, and social networking). The platform as a service enables the deployment of customized and acquired applications using tools and programming languages developed by the provider. It offers services, such as device integration, sandboxes, testing and instrumentation, and session, content, and knowledge management. Users have managed over the deployed applications but not the network, servers, OS, or storage. Users can use infrastructure as a service to deploy and run arbitrary programs, which includes processing, storage, networking, and other basic computing capabilities. Users have control over OS, storage, and networks but do not control or manage the fundamental cloud infrastructure. IaaS services include server hosting, operating systems, storage, virtual instances, load balancing, Internet access, and web servers. Finally, the DBaaS is a multilayered infrastructure with a user interface layer that accesses the service via the Internet, an application layer that accesses software and storage space services, a database layer that offers a steadfast and 
resourceful database service, and a data storage layer that encrypts data without user intervention, handles backups, and keeps track of the disk.

2.2. Cloud Deployment Service Model. Community cloud, private cloud, public cloud, and hybrid cloud are examples of cloud computing deployment models. Linthicum [7] noted that these models deploy the cloud delivery services such as DBaaS, IaaS, PaaS, and SaaS to users. In the community cloud, the infrastructure is communal to several enterprises and sustains a community with common concerns including policies, missions, objectives, compliance, and security requirements. The community cloud may exist within or outside the premises of the firm or third party that manages it. Correspondingly, in the public cloud, the infrastructure is usually owned by the cloud service provider and made available to the public or industry. The infrastructure of a private cloud, on the other hand, is administered exclusively for a single business, and it can be controlled by that organization or a third party, and it can be located within or outside the firm's premises. The infrastructure of a hybrid cloud combines two or more clouds (a combination of private, community, and public clouds). While individual clouds remain distinct entities, they are linked via homogeneous or proprietary technology, which improves data and software transferability. However, it would necessitate different security protocols and restrictions to a specific domain for the software running on it.

2.3. Cloud Computing Characteristics. Broad network access, measurable service, on-demand self-service, resource pooling, and quick elasticity are all characteristics of cloud computing. According to the Geeks for Geeks Organization website [8], ondemand self-service does not necessitate human administrators since the users themselves can manage, control, and monitor the computing resources as required. There is broad network access to the cloud implying that computing services are normally provisioned over standard networks and a variety of devices. Also, rapid elasticity means that the cloud computing services have information technology resources such as networks, servers, applications, and services that enable any service requested by users to be provided and scaled out as soon as its request is concluded. Moreover, cloud computing allows for the provision of services to clients from the same physical resource in a process known as resource pooling. Hence, the information technology resources are shared across multiple occupants and applications. Similarly, cloud computing allows for the tracking of resource utilization for each application and occupant through a measured service that enables both the user and the service provider to track usage for easy monitoring, billing, and effective use of resources.

\section{Community Cloud Adoption Factors}

Community cloud applications are affected by many factors such as ease of use, QoS, sustainability, cost, and complexity. Table 1 summarizes the main factors presented in adopting community cloud computing.

\section{Survey and Data Collection}

The information used in this study came from both primary and secondary sources. The primary data from the source were gathered through questionnaires and interviews although the details were from the secondary source academic papers, magazines, Internet, and cloud computing-based literature.

4.1. Primary Data Collection. The questionnaires were conducted with the aid of a survey monkey, an application for an online survey since this made it easy for management of questionnaires once they have been designed. It was made possible for simpler statistical analysis and can then be implemented sequentially.

4.2. Secondary Data Collection. The secondary information used for this analysis was collected from electronic databases online, like Google Scholar, IEEE, science direct, and Springer. Useful Internet articles were included.

\section{Data Analysis and Results}

This section summarizes the findings of the research conducted to determine the level of community cloud computing usage in Saudi Arabia.

5.1. Analysis of Questionnaire. To examine the scope of community cloud adoption in Saudi Arabia, two separate questionnaires were distributed a through survey monkey online. One set of questions was aimed at IT managers and telecoms firms, while the other set was aimed at IT and telecommunications companies as well as computer users who support community cloud.

Research objective 1 is as follows: to explore the awareness of employess in IT and telecommunications company and system users that enable community cloud computing, as the computing technology of the next decade.

However, the questionnaire also measured the level of awareness and intentions towards adopting community cloud computing as shown in Figure 1. $80 \%$ of the respondents rely on that community cloud access to applications from anywhere. In addition, $80 \%$ of the respondents rely on that community cloud 24 hours access to infrastructure and content, and community cloud increased openness of users to new technologies.

Research objective 2 is as follows: to analyze the adoption status of community cloud adoption in Saudi Arabia as defined by Oliveira et al. [50]. Whilst $70 \%$ of respondents agreed that they have adopted community cloud technology that is already existing as an attractive economic option to the organization, $40 \%$ of respondents agreed that provide well-known plan for adopting community cloud computing and $40 \%$ of the respondents considered that there are physical or technical reasons that prevent community cloud computing adopting in the organization as shown in Figure 2. 
TABLE 1: Summary of main factors present in adopting community cloud computing.

\begin{tabular}{|c|c|}
\hline Factors & References \\
\hline Cost & {$[9-34]$} \\
\hline Availability & {$[9,22]$} \\
\hline Compliance & [9] \\
\hline Interoperability & {$[9,27]$} \\
\hline Performance & {$[10,14,18,22,26,34-37]$} \\
\hline QoS & {$[10,14-16,31,34,38-42]$} \\
\hline Visibility & [38] \\
\hline Security & {$[11,20,21,23,34-37,39$,} \\
\hline Accuracy & {$[25,38]$} \\
\hline Attack detection & [38] \\
\hline Complexity & {$[38]$} \\
\hline Ease of use & {$[11,12,20,22,23,26,39]$} \\
\hline Sustainability & {$[12,13]$} \\
\hline Shared resource & {$[12]$} \\
\hline Transparency, resource access, efficiency, and reliability & [13] \\
\hline Feasibility & {$[44,46]$} \\
\hline Socio-economic, coordination management and provisioning, and communication & [44] \\
\hline Elasticity & {$[18]$} \\
\hline Usefulness & {$[39]$} \\
\hline Risk analysis & [39] \\
\hline Privacy & {$[20,41,42]$} \\
\hline Integration & {$[47]$} \\
\hline Flexibility & {$[47]$} \\
\hline Usefulness and incompatibility & {$[20]$} \\
\hline Trust & {$[20,21,24,42]$} \\
\hline Usage and engagement & [22] \\
\hline Adaptively & {$[20,25]$} \\
\hline Environment factors & {$[48]$} \\
\hline Compatibility, wide network access, self-service, elasticity, and integration & {$[26]$} \\
\hline Integration & {$[27]$} \\
\hline Social and economic factors & {$[42]$} \\
\hline Adequate resource & {$[26,37]$} \\
\hline Vender lock-in, security weaknesses, and lack of control & [29] \\
\hline Energy consumption and queuing delay & {$[30]$} \\
\hline $\begin{array}{l}\text { Knowledge diffusion (KD), talent acquisition (TA), intelligence creation (IC), cloud-based virtual } \\
\text { community, professional network (PN), collaboration platform (CP), and remote data storage (RS) }\end{array}$ & [49] \\
\hline Suitability & {$[31]$} \\
\hline Resource allocation & {$[31]$} \\
\hline Scalability & {$[31]$} \\
\hline
\end{tabular}

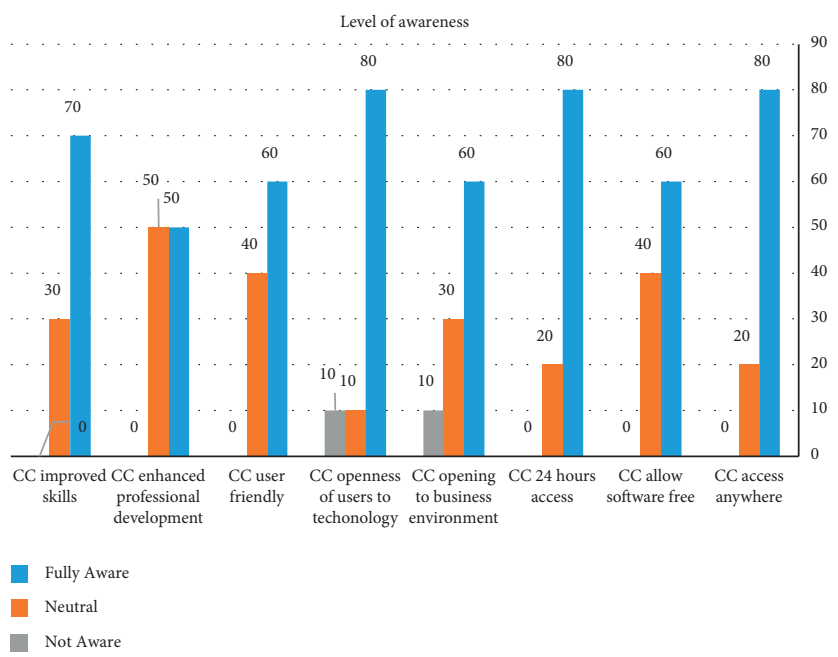

FIGURE 1: Level of awareness. 


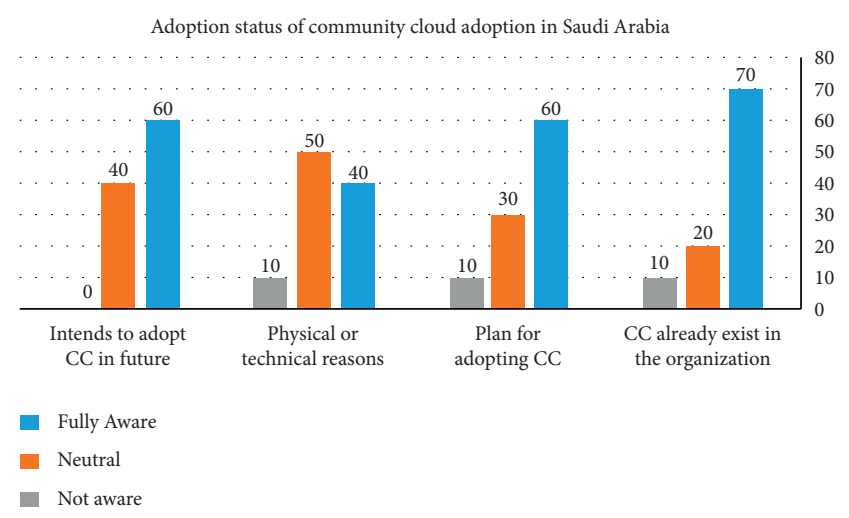

FIgUre 2: Adoption status of community cloud adoption in Saudi Arabia.

Research objective 3 is as follows: to determine the factors that influence community cloud adoption in Saudi Arabia based on factors mentioned in Table 1.

The result showed the important factors for adopting the community cloud are reducing the cost which are represented in Figure 3.

Research objective 4 is as follows: to recognize current issues affecting the adoption of community cloud in Saudi Arabia based on factors mentioned in Table 1. The result shows that the confidence is the main factor affecting the adoption of community cloud with $80 \%$ as shown in Figure 4 .

\section{Discussion}

This study aims to assess the variables influencing the adoption of Saudi Arabia community cloud computing. This has been quantitatively done with usage of online surveys. The collected results were examined. The results of study will be presented in relation to check the research goals and literature.

Objective 1 of research is as follows: to examine the understanding of workers in IT and Telecommunications companies and system users who support cloud computing as community cloud computing is the computing technology in the next era.

This objective aimed to investigate the level of awareness of this technology and the extent that they use community cloud computing. The study found that $67 \%$ of the sample respondents are fully aware of community cloud computing. Although $30 \%$ of the respondents stated to be neutral of community cloud computing, only $3 \%$ confirmed they are not aware of it as shown in Figure 5.

Objective 2 of research is as follows: to know the scale of community cloud computing adoption in Saudi Arabia.

The results show that $70 \%$ of respondents reported that community cloud technology already exists as an attractive economic option to the organization. $60 \%$ of respondents reported that the organization provides well-known plan planning to adopt community cloud computing. Furthermore, just $40 \%$ of respondents said that physical or technical barriers impede their organization from implementing community cloud computing, with $60 \%$ of respondents

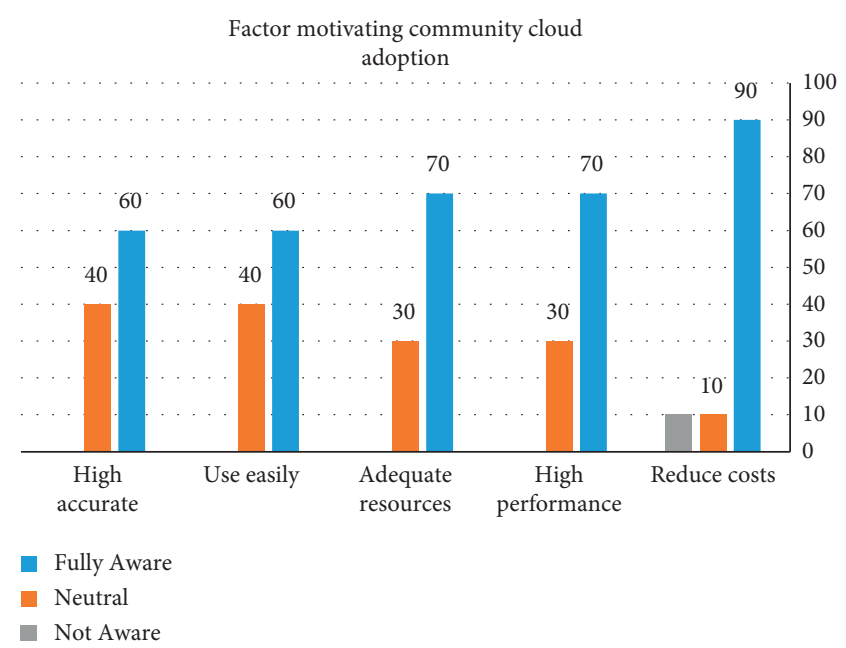

FIGURE 3: Factors influencing community cloud adoption.

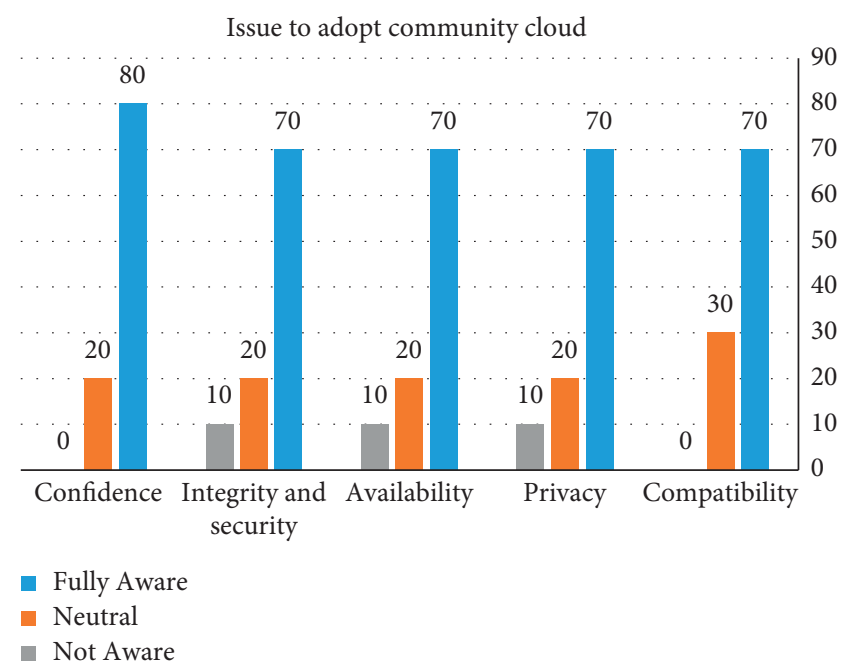

FIgURE 4: Issue influencing community cloud adoption.

reported that the organization intends to adopt community cloud in the future as shown in Figure 6.

Objective 3 of research is as follows: to establish motivation factors for the Saudi Arabia community cloud adoption.

Reducing the cost was an important factor for $90 \%$ of respondents. The results show that $70 \%$ of respondents reported that the adequate resource and performance of data as a fully aware concern. Easy to use and accuracy prove to be the concern as indicated by $60 \%$ of respondents who rated this as fully aware concern.

Objective 4 of research is as follows: to recognize existing problems impact on the adoption of community cloud computing in Saudi Arabia.

Of all the respondents, $80 \%$ expressed that the confidence of data is fully aware with organization. The integrity of data was a concern to $70 \%$ of respondents as it was rated important fully aware to develop a plan to maintain the integrity and security of data and protect an availability and privacy of the information. 


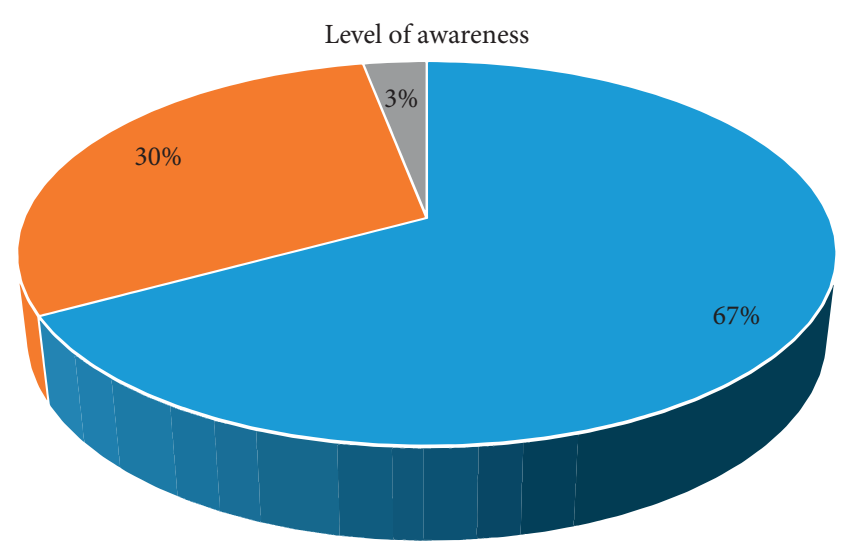

Fully Aware

- Neutral

- Not Aware

Figure 5: Percentages of level awareness.

Adoption status of community cloud adoption in Saudi Arabia

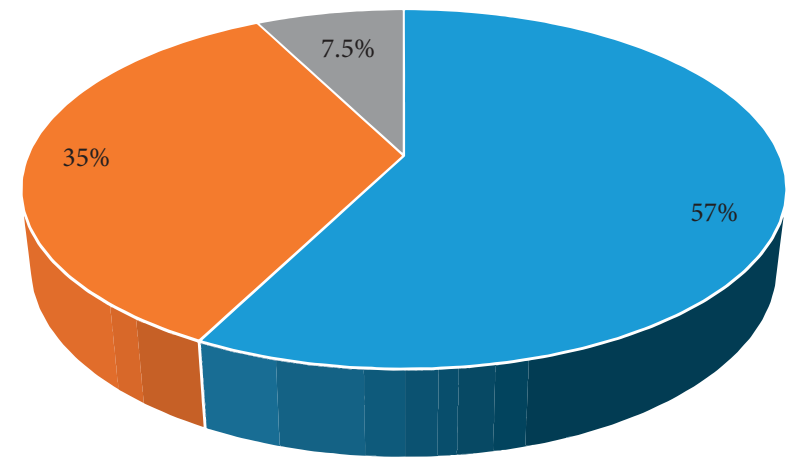

- Fully Aware

- Neutral

- Not Aware

FIgUre 6: The status of community cloud adoption in Saudi Arabia.

\section{Limitation and Conclusion}

The study's key conclusions are as follows. Overall, community cloud computing is no longer a trend but rather a technique that is expected to transform the way companies work. It requires computing power to be made available on demand and in a scalable manner as well as flexible.

The literature review looked into the factors that influence community cloud computing adoption based on previous research. The survey was used to determine the extent to which Saudi IT and telecoms firm employees and computer users have adopted the technology. The factors that influence community cloud computing adoption among Saudi IT and telecoms industry employees and computer users were investigated in this study. Our findings show that there is a large and positive association between community cloud computing awareness and community cloud computing adoption.

The analysis has a range of limitations. The survey, for example, was limited to the Asser area, restricting its generalizability. Furthermore, the quantitative approach indicates that additional qualitative approaches may help us reinforce our conclusions. Other factors, such as a mentioned in a previous study, may be useful additions. In addition, the small sample size of 100 respondents is one of the study's limitations. Future studies on this may look at different contexts, such as exploring community cloud computing adoption factors in universities or colleges.

\section{Data Availability}

The primary and secondary data used to support the findings of this study are available from the corresponding author upon request.

\section{Conflicts of Interest}

The authors declare that they have no conflicts of interest.

\section{References}

[1] D. Marinescu, Cloud Computing: Theory and Practice, pp. 1-9, Elsevier, Amsterdam, Netherlands, 2018.

[2] Y. Al-Issa, M. A. Ottom and A. Tamrawi, eHealth cloud security challenges: a survey," Journal of healthcare engineering, vol. 2019, Article ID 7516035, 15 pages, 2019.

[3] T. Alam, "Cloud computing and its role in the information technology," IAIC Transactions on Sustainable Digital Innovation (ITSDI), vol. 1, pp. 108-115, 2021.

[4] N. O'Connell, "Saudi Arabia's cloud computing regulatory framework 2.0," Tamimi.org, Dammam, Saudi Arabia, 2021, https://www.tamimi.org/law-update-articles/saudi-arabias-cl oud-computing-regulatory-framework-2-0/.

[5] M. Al-Ruithe, E. Benkhelifa, and K. Hameed, "Current state of cloud computing adoption - an empirical study in major public sector organizations of Saudi Arabia (KSA)," Procedia Computer Science, vol. 110, pp. 378-385, 2018.

[6] National Institute of Standards and Technology, "NIST releases evaluation of cloud computing services based on NIST SP 800145," NIST, Gaithersburg, MA, USA, 2021, https://www.nist. gov/news-events/news/2018/02/nist-releases-evaluation-cloudcomputing-services-based-nist-sp-800-145.

[7] D. Linthicum, "Approaching cloud computing performance," IEEE Cloud Computing, vol. 5, no. 2, pp. 33-36, 2018.

[8] Geeks for Geeks Organization, "Characteristics of cloud computing - GeeksforGeeks. GeeksforGeeks," 2021, https://www. geeksforgeeks.org/characteristics-of-cloud-computing/amp/.

[9] K. A. Rodrigues de Castro, "Feasible community cloud architecture for provisioning infrastructure as a service in the government sector," in Proceedings of the 20th Annual International Conference on Digital Government Research, pp. 35-40, Dubai UAE, June 2019.

[10] K. Dubey, M. Y. Shams, S. C. Sharma, A. Alarifi, M. Amoon, and A. A. Nasr, "A management system for servicing multiorganizations on community cloud model in secure cloud environment,” IEEE Access, vol. 7, 2019 p, Article ID 159535.

[11] S. Yokoyama and N. Yoshioka, "A distributed cloud architecture for academic community cloud," Communications in Computer and Information Science, Springer, Berlin, Germany, pp. 169-186, 2015.

[12] R. Baig, F. Freitag, and L. Navarro, "On the sustainability of community clouds in guifi.net," in Proceedings of the International Conference on the Economics of Grids, Clouds, 
Systems, and Services, pp. 265-278, Springer:Cham, Athens, Greece, September 2016.

[13] A. Kawa and M. Ratajczak-mrozek, "Cloud Community in Logistics E-Cluster Industry Clusters and E-Clusters as a Network Structure," in Proceedings of the Asian Conference on Intelligent Information and Database Systems, pp. 495-503p, Phuket, Thailand, April 2014.

[14] M. D. Os and G. Bressan, "A community cloud for a real-time financial application - requirements, architecture and mechanisms," in proceedings of the International Conference on Algorithms and Architectures for Parallel Processing, no. 1, pp. 364-377, Springer:Cham, Dalian, China, August 2014.

[15] Y. Wu, M. Su, W. Zheng, K. Hwang, and A. Y. Zomaya, "Associative big data sharing in community clouds," IEEE Cloud Computing, vol. 2, no. 6, pp. 64-73, 2015.

[16] S. Filiposka and C. Juiz, "Community-based complex cloud data center"' Physica A: Statistical Mechanics and Its Applications, vol. 419, pp. 356-372, 2015.

[17] A. Adimabua Ojugo, "Dependable community-cloud framework for smartphones," American Journal of Networks and Communications, vol. 4, no. 4, pp. 95-103, 2015.

[18] K. Ahmad, A. Wahid, M. P. Quadri, and A. Fathima, "Parallel virtualization in IaaS in community cloud," in Proceedings of the 2015 Fifth International Conference on Communication Systems and Network Technologies, pp. 1071-1075, IEEE, Gwalior, India, April 2015.

[19] S. L. Mohan, Y. R. Reddy, and G. R. Gangadharan, "Compac-a pricing model for community cloud," in Proceedings of the 2017 International Conference on Advances in Computing, Communications and Informatics (ICACCI), pp. 2033-2039, IEEE, Udupi, India, September 2017, p.

[20] F. Shirazi and A. Qbal, "Community clouds within M-commerce: a privacy by design perspective," Journal of Cloud Computing, vol. 6, no. 1, 2017.

[21] R. E. Yoro and A. A. Ojugo, "An intelligent client-trusted and dependable security framework to ease smartphone portability on community cloud-computing," Journal of Computer Networks, vol. 6, no. 1, pp. 1-7, 2019, p.

[22] R. Baig, F. Freitag, A. Moll, L. Navarro, R. Pueyo, and V. Vlassov, "Cloud-based community services in community networks," in Proceedings of the 2016 International Conf on Computing, Networking and Communications (ICNC), pp. 1-5, IEEE, Kauai, HI, USA, February 2016.

[23] R. Baig, F. Freitag, and L. Navarro, "Fostering collaborative edge service provision in community clouds with docker," in Proceedings of the 2016 IEEE International Conference on Computer and Information Technology, pp. 560-567, CIT, Nadi, Fiji, December 2017.

[24] F. Hao, D. S. Park, J. Kang, and G. Min, "A two-layer multicommunity-cloud/cloudlet social collaborative paradigm for mobile edge computing," IEEE Internet of Things Journal, vol. 6, no. 3, pp. 4764-4773, 2018, p.

[25] M. Giacobbe, M. Scarpa, R. Di Pietro, and A. Puliafito, “An Energy-Aware brokering algorithm to improve sustainability in community cloud," in Proceedings of the 6th International Conference on Smart Cities and Green ICT Systems(SMARTGREENS), pp. 166-173, Porto Portugal, April 2017.

[26] S. Bruque-Cámara, J. Moyano-Fuentes, and J. M. MaqueiraMarín, "Supply chain integration through community cloud: effects on operational performance," Journal of Purchasing and Supply Management, vol. 22, no. 2, pp. 141-153, 2016.

[27] T. M. Al-Mashat, F. A. El-Licy, and A. I. Salah, "Semantic cloud community framework for services provision," in Proceedings of the International Conference on Advanced
Intelligent Systems and Informatics, pp. 222-231, Cham: Springer, Cairo, Egypt, September 2017.

[28] B. Saovapakhiran and M. Devetsikiotis, "Enhancing computing power by exploiting underutilized resources in the community cloud," in Proceedings of the 2011 IEEE International Conference on Communications (ICC), pp. 1-6, IEEE, Kyoto, Japan, June 2011, p.

[29] G. Garlick, "Improving resilience with community cloud computing," in Proceedings of the 2011 6th International Conference on Availability, Reliability and Security, pp. 650655, IEEE, Vienna, Austria, August 2011.

[30] S. Ren and M. Van der Schaar, "Efficient resource provisioning and rate selection for stream mining in a community cloud," IEEE Transactions on Multimedia, vol. 15, no. 4, pp. 723-734, 2013.

[31] A. M. Khan, X. Vilaça, L. Rodrigues, and F. Freitag, "Towards incentive-compatible pricing for bandwidth reservation in community network clouds," in Proceedings of the International Conference on the Economics of Grids, Clouds, Systems, and Services, pp. 251-264, Springer, Cham, Cluj-Napoca, Romania, September 2015, p.

[32] F. Shirazi, "An intelligent interactive home care system: an MPLS-Based community cloud," in Proceedings of the International Conference on Human Interface and the Management of Information, pp. 207-216, Springer, Las Vegas, NV, USA, July 2013, p.

[33] T. Mullins, A. Bagula, S. Rhekis, and N. Boudriga, "service provisioning for lightweight community cloud infrastructures," in Proceedings of the International Conference On Information Resources Management (Conf-Irm), p. 21, May 2016, Cape Town, South Africa.

[34] J. Li, Z. Lu, W. Zhang et al., "“'SERAC3: smart and economical resource allocation for big data clusters in community clouds," Future Generation Computer Systems, vol. 85, pp. 210-221, 2018.

[35] S. Valluripally, M. Raju, P. Calyam et al., "Community cloud architecture to improve use accessibility with security compliance in health big data applications,", in Proceedings of the 20th International Conference on Distributed Computing and Networking, pp. 377-380, Bangalore India, January 2019.

[36] F. Baiardi and D. Sgandurra, "Securing a community cloud," in Proceedings of the IEEE 30th International Conference on Distributed Computing Systems Workshops, pp. 32-41, IEEE, Genoa, Italy, June 2010.

[37] N. Apolónia, R. Sedar, F. Freitag, and L. Navarro, "Leveraging low-power devices for cloud services in community networks," in Proceedings of the 2015 3rd International Conference on Future Internet of Things and Cloud, pp. 363-370, IEEE, Rome, Italy, August 2015.

[38] O. A. Wahab, J. Bentahar, H. Otrok, and A. Mourad, "Misbehavior detection framework for community-based cloud computing," in Proceedings of the 2015 3rd International Conference on Future Internet of Things and Cloud, pp. 181188, IEEE, Rome, Italy, August 2015.

[39] A. M. Khan, F. Freitag, S. Gupta, V. Muntès-Mulero, J. Dominiak, and P. Matthews, "On supporting service selection for collaborative multi-cloud ecosystems in community networks," in Proceedings of the 2015 IEEE 29th International Conference on Advanced Information Networking and Applications, pp. 634-641, IEEE, Gwangju, Republic of Korea, March 2015.

[40] S. Wen, J. Yang, G. Chen, J. Tao, X. Yu, and A. Liu, "Enhancing service composition by discovering cloud services community," IEEE Access, vol. 7, pp. 32472-32481, 2019. 
[41] P. Zhao and X. Yang, "Joint optimization of admission control and rate adaptation for video sharing over multirate wireless community cloud," China Communications, vol. 13, no. 8, pp. 24-40, 2016.

[42] A. M. Khan, F. Freitag, and L. Rodrigues, "Current trends and future directions in community edge clouds," in Proceedings of the 2015 IEEE 4th International Conference on Cloud Networking (CloudNet), pp. 239-241, IEEE,p, Niagara Falls, Canada, October 2015.

[43] Y. Zhang, F. Patwa, R. Sandhu, and B. Tang, "Hierarchical secure information and resource sharing in OpenStack community cloud," in Proceedings of the 2015 IEEE International Conference on Information Reuse and Integration, pp. 419-426, San Francisco, CA, USA, August 2015.

[44] M. Selimi and F. Freitag, "Towards application deployment in community network clouds," in Proceedings of the International Conference on Computational Science and Its Applications, pp. 614-627, Springer, Cham, Cagliari, Italy, July 2014.

[45] H. M. Alsaghier, S. S. Ahamad, S. K. Udgata, and L. S. S. Reddy, "A secure and lightweight protocol for mobile DRM based on DRM community cloud (DCC)," in Proceedings of the 5th International Conference on Frontiers in Intelligent Computing: Theory and Applications, pp. 475-483, Springer, Singapore, March 2017, p.

[46] R. Baig, F. Freitag, and L. Navarro, "Cloudy in guifi. net: establishing and sustaining a community cloud as open commons," Future Generation Computer Systems, vol. 87, pp. 868-887, 2018, p.

[47] J. P. Barraca, A. Matos, and R. L. Aguiar, "User centric community clouds," Wireless Personal Communications, vol. 58, no. 1, pp. 31-48, 2011.

[48] F. Hao, G. Min, J. Chen et al., "An optimized computational model for multi-community-cloud social collaboration," IEEE Transactions on Services Computing, vol. 7, no. 3, pp. 346-358, 2014.

[49] C. W. Keung, "A conceptual model of cloud-based virtual community for BIM innovation and promotion," in Proceedings of the 21st International Symposium on Advancement of Construction Management and Real Estate, pp. 45-52, Springer, Singapore, December 2018.

[50] T. Oliveira, M. Thomas, and M. Espadanal, "Assessing the determinants of cloud computing adoption: an analysis of the manufacturing and services sectors," Information \& Management, vol. 51, no. 5, pp. 497-510, 2014. 